\title{
NIHR's research signals in The BMJ
}

\author{
A new series of selected research summaries written for busy clinicians
}

\author{
Sophie Cook research editor ${ }^{1}$, Tara Lamont director ${ }^{2}$, Rob Cook deputy director-clinical ${ }^{2}$, Tansy \\ Evans acting deputy director ${ }^{2}$, Peter Davidson clinical adviser ${ }^{2}$
}

${ }^{1}$ The BMJ, London, UK; ${ }^{2} \mathrm{NIHR}$ Dissemination Centre, University of Southampton, Southampton, UK

Decisions in healthcare are complex and different for every person. Keeping up to date with new research and guidance is key to dealing with uncertainty and delivering high quality personalised care. Both clinicians and patients need robust summaries and shortcuts to help put the findings of new studies into the context of wider evidence and clinical guidelines. With at least 75 trials and 11 systematic reviews published every day (numbers are likely to have risen since this 2010 estimate), ${ }^{1}$ filters and selection processes are needed.

The National Institute for Health Research (NIHR) is the largest public funder of health research in the UK, providing infrastructure support and funding for more than 350 substantive clinical, social care, and public health studies each year. ${ }^{2}$

NIHR programmes work with frontline healthcare staff and others to identify information gaps and develop high quality research to help fill them. ${ }^{3}$ Focusing on uncertainties that have been identified as important by clinicians, managers, patients, and the public, ${ }^{4}$ NIHR aims to maximise the value of research by asking the right question in the right way. ${ }^{5}$ Recent studies informing common clinical problems include a randomised trial evaluating the safest position for labour in nulliparous women with an epidural ${ }^{6}$ and a trial assessing the use of adrenaline for cardiac arrest out of hospital. ${ }^{7}$

Recognising the need for filters and summaries, NIHR set up a dissemination centre in 2015 to help translate research results into practice. Every week, the centre produces three to five NIHR Signals: critical summaries of NIHR and other research, written following the principles of good journalism with declarative titles, prominent key findings, and direct, plain English.

Readers of The BMJ tell us that they need more and better information about relevant healthcare research in an easily accessible form. So this week, we are launching a collaboration between The BMJ and the NIHR Dissemination Centre, bringing a selection of these summaries to our readers.

The selection process for NIHR Signals includes an assessment of research quality using accepted critical appraisal checklists (https://casp-uk.net/), risk of bias tools, and careful consideration of the clinical implications of the findings, with reference to relevant guidelines and service context. The process is described in detail on the NIHR website. ${ }^{8}$

All research abstracts that pass initial screening are then reviewed and rated for relevance and importance by raters drawn from a pool of over 1400 clinicians, managers, and patients. Less than a quarter of all NIHR funded studies are selected for NIHR Signals, along with just $1-2 \%$ of the other reviews and landmark studies screened from selected journals. People can sign up to receive all signals or just those relating to their area of interest (https://www.dc.nihr.ac.uk/email-sign-up). All editorial staff involved in the creation of NIHR Signals adhere to The BMJ's strict conflicts of interest policy for education content. ${ }^{9}$

This collaboration will help bring together high quality NIHR research published in a range of journals. We will focus on NIHR funded research as this has been funded to clarify areas of clinical uncertainty for the NHS identified by panels of scientists, clinicians, and patients. We will select for publication those summaries likely to be of greatest practical value to our diverse readership of clinicians and welcome your feedback to help inform this process.

It's a noisy world out there, and we hope the new series will help busy clinicians identify the research signals most likely to help their patients, inform their practice, and improve quality of care.

Competing interests: We have read and understood BMJ policy on declaration of interests and have no relevant interests to declare.

Provenance and peer review: Commissioned; not externally peer reviewed.

Bastian H, Glasziou P, Chalmers I. Seventy-five trials and eleven systematic reviews a day: how will we ever keep up?PLOS Med 2010;7:e1000326. 10.1371/journal.pmed.1000326 20877712

NIHR. NIHR annual report 2016/17. https://www.nihr.ac.uk/about-us/publications/

3 Raftery J, Powell J. Health technology assessment in the UK. Lancet 2013;382:1278-85. 10.1016/S0140-6736(13)61724-9 24120204

4 Farmer A, Milne R, Walley T. Research to decrease areas of clinical uncertainty. BMJ 2011:342:d369. 10.1136/bmi.d369 21296837

5 Chalmers I, Glasziou P. Avoidable waste in the production and reporting of research evidence. Lancet 2009;374:86-9. 10.1016/S0140-6736(09)60329-9 19525005 
$6 \quad$ Epidural and Position Trial Collaborative Group. Upright versus lying down position in second stage of labour in nulliparous women with low dose epidural: BUMPES randomised controlled trial. BMJ 2017;359:j4471.29046273

7 Perkins GD, Ji C, Deakin CD, etal . PARAMEDIC2 Collaborators. A randomized trial of epinephrine in out-of-hospital cardiac arrest. N Engl J Med 2018;379:711-21.10.1056/NEJMoa1806842 30021076

8 NIHR. How we select research for a signal. https://www.dc.nihr.ac.uk/about/what-makesan-nihr-signal.htm
9 Chew M, Brizzell C, Abbasi K, Godlee F. Medical journals and industry ties. BMJ 2014;349:g7197. 10.1136/bmj.g7197 25432164

Published by the BMJ Publishing Group Limited. For permission to use (where not already granted under a licence) please go to http://group.bmj.com/group/rights-licensing/ permissions 